\title{
Dissecting Motivational Circuitry to Understand Substance Abuse
}

\author{
Robert A. Wheeler ${ }^{1}$ and Regina M. Carelli ${ }^{1,2}$ \\ ${ }^{1}$ Department of Psychology, University of North Carolina, Chapel Hill, Chapel Hill, NC 27599 \\ ${ }^{2}$ Neuroscience Center, University of North Carolina, Chapel Hill, Chapel Hill, NC 27599
}

\section{Summary}

\begin{abstract}
An important goal of cocaine addiction research is to understand the neurobiological mechanisms underlying this disease state. Here, we review studies from our laboratory that examined nucleus accumbens (NAc) cell firing and rapid dopamine signaling using electrophysiological and electrochemical recordings in behaving rodents. A major advantage of these techniques is that they allow for the characterization of NAc activity and rapid dopamine release during specific phases of motivated behavior. Moreover, each approach enables an examination of the dynamic nature of NAc signaling as a function of factors such as hedonics and associative learning. We show that NAc neurons differentially respond to rewarding and aversive stimuli and their predictors in a bivalent manner. This differential responding is modifiable and can be altered by the presentation of other natural rewards or cocaine. Likewise, the dynamic nature of NAc cell firing is also reflected in the differential activation of distinct populations of NAc neurons during goal-directed behaviors for natural versus drug rewards, and the heightened activation of some NAc neurons following cocaine abstinence. Our electrochemical data also show that rapid dopamine signaling in the NAc reflects primary rewards and their predictors and appears to modulate specific NAc neuronal responses. In some cases, these influences are observed in a regionally specific manner that matches previous pharmacological manipulations. Collectively, these findings provide critical insight into the functional organization of the NAc that can be used to guide additional studies aimed at dissecting the neural code underlying compulsive drug-seeking behavior.
\end{abstract}

\section{Keywords}

reward; aversion; taste; drug abuse; cocaine; nucleus accumbens

\section{Introduction}

Dissecting the neural circuitry mediating reward-seeking behaviors is essential for understanding the manner by which motivational systems become dysfunctional in the disease of addiction. Drug addiction has been characterized by multiple factors such as withdrawal (Solomon and Corbit, 1974), hedonics (Wise and Bozarth, 1987), sensitization (Robinson and Berridge, 1993), and learning (Everitt and Robbins, 2005; Hyman et al., 2006; Wise, 2004). It is quite likely that all of these components contribute to the pathology. An important part of this circuit, the nucleus accumbens (NAc), is ideally positioned to be responsive to numerous

(C) 2008 Elsevier Ltd. All rights reserved.

Corresponding author: Regina M. Carelli, PhD, Email: rcarelli@unc.edu, Phone: 919-962-8775, Fax: 919-962-2537.

Publisher's Disclaimer: This is a PDF file of an unedited manuscript that has been accepted for publication. As a service to our customers we are providing this early version of the manuscript. The manuscript will undergo copyediting, typesetting, and review of the resulting proof before it is published in its final citable form. Please note that during the production process errors may be discovered which could affect the content, and all legal disclaimers that apply to the journal pertain. 
aspects of this disease and to influence motivated behavior accordingly (Mogenson et al., 1980). In fact, since the discovery that the ventral striatum is necessary to initiate and maintain motivated behavior, researchers are discovering that the processing of motivation, learning and hedonics are embedded within it. More recent findings have indicated that there appears to be subregional specificity in NAc function for stimuli that predict cocaine versus the pharmacological effects of the drug. That is, the core of the NAc appears to encode cocaineassociated stimuli while the shell is generally responsive to the primary reinforcing properties of reinforcers. For example, the core (but not the shell) subregion is necessary for the proper responses to cues associated with both natural (Parkinson et al., 1999) and drug rewards (Di Ciano and Everitt, 2001; Fuchs et al., 2004). Furthermore, dopamine function in the core subregion of the NAc has been implicated in mediating the association of natural reward-related stimuli (Day et al., 2007; Parkinson et al., 2002) and the proper behavioral responses to stimuli that predict cocaine (Di Chiara et al., 2004; Ito et al., 2000; Ito et al., 2004). In contrast, the shell appears to be more responsive to the primary reinforcing or motivational properties of drugs and natural rewards (Di Chiara et al., 2004; Kelley et al., 2002; Kelley and Swanson, 1997; Pecina and Berridge, 2005); however see (Bassareo et al., 2007; Cheer et al., 2007).

Here, we review electrophysiological and electrochemical research conducted in our laboratory that examined nucleus accumbens (NAc) cell firing and rapid dopamine release in awake, behaving rodents. Our findings indicate that the processing of various types of information by NAc neurons (e.g., hedonic valence, goal-directed behavior and learning) are functionally segregated within this structure but modulated by each other. As such, our findings provide crucial insight into the functional organization of the NAc mediating normal reward encoding and goal-seeking behaviors, and how these factors interact to produce motivated behavior that becomes pathological in the disease of addiction.

\section{Nucleus Accumbens Neurons Exhibit Differential Activity to Rewarding and Aversive Stimuli}

Reinforcing stimuli produce motivated behavior by engaging sensory systems and inducing a hedonically pleasing feeling. While this feeling must have a neural representation, it is not a simple task to investigate the neural processing of hedonic information using animal models. Fortunately, affective state can be assessed in non-humans and investigators have shown that the NAc modulates the processing of rewarding and aversive stimuli (Mahler et al., 2007; Pecina and Berridge, 2005; Reynolds and Berridge, 2002, 2003; Roitman et al., 2005; Wheeler et al., 2008). Most investigations on the role of the NAc in reward processing have examined this system when animals are engaged in goal-directed behavior (Carelli et al., 2000; Carelli and Wondolowski, 2003; Nicola et al., 2004; Wise and Rompre, 1989; Yun et al., 2004).

However, for hedonic processing to be investigated separately from reward seeking behavior, studies must dissociate the two phenomena. To this end, studies have examined NAc activity during direct application of palatable and unpalatable taste stimuli independent of operant contingencies (Roitman et al., 2005; Wheeler et al., 2005). These studies employed electrophysiological recording techniques in awake behaving rodents, as described in detail elsewhere (Roitman et al., 2005). Briefly, NAc activity was recorded differentially between active and inactive electrodes using a commercially available neurophysiology system (multichannel acquisition processor (MAP) system; Plexon Inc., Dallas, TX). After waveform sorting, firing rates of individual neurons were aligned to the behaviorally relevant event (in this case, the solenoid opening onset for the intraoral infusion) and analyzed using commercially available software (NeuroExplorer, Plexon Inc., Dallas, TX). Using this approach, we showed that intraoral infusions of a palatable sucrose solution are associated, predominantly, with transiently reduced firing rates for the majority of responsive NAc neurons (Roitman et al., 2005). This response profile is illustrated in the perievent histogram (PEH) and raster display for one NAc neuron in Figure 1A. In contrast, NAc neurons display 
predominantly excitatory responses during infusion of an aversive tastant, such as a bitter quinine solution, as shown for another neuron in Figure 1B. Importantly, in this study rats were not engaged in goal-directed behavior during electrophysiological recording because the tastant was directly administered into the oral cavity, yet the differential signal persisted. As this pattern of neural activity cannot be attributed simply to goal-seeking, it likely reflects the hedonic valence of the taste stimulus. Moreover, these data suggest that the NAc bivalently encodes rewarding and aversive stimuli. That is, as illustrated in the piecharts in Figure 1 (bottom), the predominant response (approximately 75\%) of all phasically active NAc neurons to the application of a palatable taste stimulus such as sucrose is a reduction (inhibition) in firing rate (Figure 1C) while the predominant response of neurons (again, approximately 75\%) to an unpalatable taste stimulus such as quinine is an increase (excitation) in activity (Figure 1D).

Interestingly, we and others have shown that some NAc neurons are modulated not only by taste palatability, but also by relative reward value (Taha and Fields, 2005; Wheeler et al., 2005). That is, a small percentage of NAc neurons that exhibit altered firing rates in response to rewarding tastants such as sucrose, change their activity for the same sweet taste, due to its devaluation by the presentation of a more palatable sucrose solution. Such findings are termed "contrast effects" (Flaherty, 1999); an example of this type of a design and one such NAc neural response are illustrated in Figure 2. In this study, rats were given discrete intraoral infusions of a palatable $0.05 \mathrm{M}$ sucrose solution $(133 \mu \mathrm{l} /$ infusion over $4 \mathrm{~s})$ at a rate of one infusion per minute. The rats were next infused with the same solution, but its delivery was alternated with the presentation of a more palatable 0.5 M sucrose solution (Figure 2A). We showed that the behavioral and electrophysiological responses for the low concentration of sucrose were diminished as the sweet taste was devalued by its presentation with the more palatable natural reward. An example of one neuron showing this dynamic change in firing pattern is illustrated in Figure 2B. In this case, the cell exhibited a typical inhibitory response during baseline application of the $0.05 \mathrm{M}$ sucrose solution (Figure 2B, left). However, the same neuron showed no change in firing rate to the same sucrose solution when presented in alteration with a more palatable $0.5 \mathrm{M}$ sucrose solution (Figure 2B middle), although the neuron showed a pronounced inhibitory response during application of the higher concentration (Figure 2B, right). Similar diminished neuronal responses were found in a small population (approximately 3\%) of NAc neurons (Taha and Fields, 2005; Wheeler et al., 2005) and as such may not dramatically alter the output of the NAc, especially compared to the response pattern observed during the intraoral infusion of a bitter and aversive stimulus, such as quinine (see Figure 1B). Nevertheless, findings that a small population of NAc neurons encodes "contrast effects" involving natural rewards indicate that this system tracks reward comparison information.

Differential signaling in the NAc for rewarding and aversive stimuli is complex, making conclusions regarding the behavioral significance and putative output targets difficult to determine. One proposal is that the predominant inhibitory response of NAc neurons to rewarding stimuli may function to disinhibit ventral pallidal neurons (the NAc primary efferent) and thereby gate appetitive behavior (Taha and Fields, 2006). In support, pharmacological inhibitions of the NAc shell have been shown to promote consummatory behavior (Kelley, 2004). However, hedonic processing is also known to contribute to appetitive behavior, and NAc neurons appear to convey hedonic information (Taha and Fields, 2005). For example, we have shown that inhibitions in NAc cell firing to palatable tastants persist even when sucrose or saccharin is intraorally infused in the absence of goal-directed behavior (e.g., Figure 1). Moreover, pharmacological studies have shown that inhibition of the NAc shell increase hedonic responses to palatable tastants (Reynolds and Berridge, 2002), suggesting that this inhibitory signal directly modulates consummatory behavior. Together, these findings suggest an overlap in the encoding of appetitive/consummatory information with a hedonic signal that modulates motivated behavior. We plan future studies combining 
electrophysiological and pharmacological manipulations to clarify NAc signals and their downstream targets and determine their relevance to motivated behavior.

\subsection{Role of Dopamine and Other Neurotransmitters in Reward and Aversion}

The precise role of specific neurotransmitters in the NAc in hedonic processing has been the subject of some controversy over the last few decades. Early studies incorporating pharmacological manipulations of this structure gave rise to the view that dopamine release in the NAc mediates the hedonic impact of rewarding stimuli (Wise et al., 1978). However, the observation that depletion of NAc dopamine does not reduce hedonic responses (Berridge et al., 1989) or food intake (Baldo et al., 2002) suggests that dopamine does not mediate primary reinforcement. Moreover, these same manipulations alter subsequent motivated behavior creating 'extinction-like' effects. For example, under dopamine receptor antagonism, rats will traverse a runway and consume a food reward but on subsequent trials exhibit retardation of extinction, behaving as if trained under a schedule of partial reinforcement (Ettenberg and Camp, 1986). Similar studies suggest that dopamine signaling does not mediate hedonic or consummatory responses, but instead may influence future motivated behavior (Wise, 2004; Wise and Raptis, 1986).

While dopamine neurotransmission appears to have a secondary role in primary reinforcement, other neurotransmitter systems strongly impact hedonic processing. Opioid, GABA, and cannabanoid agonist microinfusions into the NAc shell increase appetitive behavior and hedonic responses for gustatory stimuli (Kelley et al., 2002; Kelley and Swanson, 1997; Mahler et al., 2007; Pecina and Berridge, 2000, 2005; Reynolds and Berridge, 2002). Interestingly, pharmacological manipulations of the NAc that increase affective oro-facial responses to the taste of sweet solutions are specific to the dorsal shell subregion, a so called 'hedonic hotspot' (Pecina and Berridge, 2005; Pecina et al., 2006). Further, the shell region appears to be involved in processing the primary reinforcing effects of drugs of abuse (Bassareo et al., 2007; Ito et al., 2004). Electrophysiological and pharmacological studies of this region have shown that, generally, increases in motivated behavior for a given stimulus appear to be driven by decreased activity in the NAc shell (Carlezon and Wise, 1996). As noted above, electrophysiological studies are consistent with the pharmacological data. That is, findings of predominantly inhibitory NAc electrophysiological responses to an appetitive stimulus (e.g., sucrose), and excitatory responses to an aversive stimulus (Figure 1), have been reported by our laboratory and others (Nicola et al., 2004; Roitman et al., 2005; Taha and Fields, 2005, 2006). Thus, while the precise role of dopamine in hedonic processing is less clear, the NAc does indeed encode the hedonic valence of primary reinforcers via other neurotransmitter actions involving GABA, cannabinoids, and opioids.

\section{NAc Neurons Differentially Encode Goal-Directed Behaviors for Natural and Drug Rewards}

As NAc neurons are responsive to rewarding stimuli such as sucrose and saccharin, one might think that goal-directed behaviors for all rewards are encoded similarly in this region. Surprisingly, this is not the case. We have shown that NAc neurons exhibit differential, nonoverlapping firing patterns during goal-directed behaviors for a "natural" reward versus cocaine (Carelli, 2002; Carelli et al., 2000; Carelli and Wondolowski, 2003). This differential activity is illustrated for two NAc neurons in Figure 3. In this study, animals were first trained to press a lever for water reinforcement (delivery into a drinking receptacle next to the lever). Once trained, animals learned to press a second lever for intravenous cocaine. A multiple schedule was implemented whereby animals responded on the first lever for water, followed by a $20 \mathrm{~s}$ timeout period (levers retracted) and extension of the second lever for cocaine selfadministration. As shown for one representative neuron in the left panel of Figure 3, the cell 
displayed a clear increase in firing rate within seconds following the response for water reinforcement (Figure 3A) but shifted to no change in firing (i.e., nonphasic activity) relative to the cocaine reinforced response (Figure 3B). Another NAc neuron shown in the right portion of Figure 3 exhibited an opposite firing profile. In this case, the neuron displayed nonphasic activity during responding for water (Figure 3C), and a dynamic shift to phasic firing during cocaine self-administration (Figure 3D). In sum, approximately $92 \%$ of all phasically active NAc neurons exhibit differential, nonoverlapping firing patterns relative to lever press responding for a natural (water, food, sucrose) versus drug (cocaine) reward. Moreover, these differential firing profiles were observed in animals experiencing repeated cocaine selfadministration training (Carelli et al., 2000) or within the first day of cocaine exposure (Carelli and Wondolowski, 2003).

We have also shown differential neuronal firing patterns during multiple schedules involving food and cocaine self-administration (Carelli et al., 2000). These findings are consistent with a report by Bowman and colleagues (1996) showing differential activation of NAc neurons during responding for juice and cocaine in nonhuman primates (Bowman et al., 1996).

Moreover, the presentation of cocaine-associated stimuli alone have the capacity to selectively activate the subset of NAc neurons that process information related to cocaine-seeking behaviors but not those cells that encode information about water reinforcement (Carelli and Ijames, 2001). So while the NAc is critical for the engagement of motivated behavior for natural and drug rewards, our studies revealed that this structure is comprised of complex, heterogeneous 'microcircuits' whereby different NAc neurons encode information related to goal-directed behaviors for natural versus drug reward.

\section{Cocaine Experience Dynamically Modulates NAc Activity for Natural Rewards}

In our multiple schedule studies described above, natural and drug reward were not repeatedly paired. That is, animals were typically trained to press one lever for water, and a second lever for intravenous cocaine, and only a few sessions involved both reinforcers in the multiple schedule design. However, others have shown that animals will actually respond less for a previously palatable natural reward when it comes to predict an abused drug such as cocaine or amphetamine (Grigson and Twining, 2002; Wise et al., 1976). We characterized this phenomenon in a recent study and showed that the repeated pairing of a sweet tastant with cocaine results in an aversive state that is reflected in behavior and NAc neurophysiology (Wheeler et al., 2008). Specifically, animals were trained to discriminate a sweet taste (e.g., orange flavored saccharin solution) that predicted cocaine availability from another equally sweet taste (e.g., grape flavored saccharin solution of the same concentration) that predicted saline availability. After several taste-drug and taste-saline pairings the rats developed a strong aversion to the taste that predicted cocaine. This aversive state was reflected in changes in the oro-facial expression of the rat during tastant infusion. That is, the tastant paired with saline elicited classic appetitive taste reactivity while the tastant paired with cocaine elicited aversive taste reactivity (e.g., gapes).

Moreover, this aversive state was reflected in a shift in the activity of NAc neurons. Unlike the relatively small neural devaluation of a sweet taste by a more palatable concentration of the same reward observed in Figure 2, a different and more profound change occurred in NAc neuronal firing profiles when the tastant was paired with drug. That is, NAc neurons shifted from predominately inhibitory activity to predominately excitatory firing during infusion of the sweet tastant paired with cocaine availability. An example of one neuron showing such a shift is illustrated in Figure 4 (top). In this case, the neuron displayed the typical inhibition in firing rate during infusion of the sweet tastant paired with the availability to self-administer saline (Figure 4A). However, this same neuron displayed an increase in firing rate during 
infusion of the other tastant of the same saccharin concentration but that was explicitly paired with cocaine self-administration (Figure 4B). The piecharts in the bottom of Figure 4 show the shift in the firing pattern distribution for the population of NAc neurons from primarily inhibitory during infusion of the tastant paired with saline (Figure 4C) to primarily excitatory when the tastant was paired with cocaine self-administration (Figure 4D).

We believe that the increase in excitatory responses to the drug-associated tastant is reflective of multiple phenomena. First, the change in NAc patterned activity resembles the response to an innately aversive quinine solution (Figure 1B), suggesting a bivalent representation of rewarding and aversive stimuli in the NAc. That is, when something is perceived as rewarding, primarily inhibitions in NAc cell firing are observed and the opposite occurs for substances associated with aversion. Second, the switch to excitations for the cocaine-predictive taste stimulus likely reflects the learned association with the drug. Of course, these possibilities are not mutually exclusive. The enhanced activity of NAc neurons to the cocaine-associated stimulus likely reflects an aversive state that developed as the association with impending drug availability was learned. The importance of this learned association is highlighted by the finding that animals were more motivated to consume the drug following the manifestation of this learned aversive state.

An important issue raised by the aforementioned studies concerns the role of dopamine in hedonics and reward comparison. As discussed above (section 2.1), a wealth of evidence suggests that dopamine does not directly mediate the hedonic signal of primary reinforcers, but instead guides subsequent motivated behavior (Baldo and Kelley, 2007;Wise, 2004). Electrochemical techniques, such as fast scan cyclic voltammetry (FSCV), are ideally suited to address this question since chemical changes (e.g., dopamine) can be obtained with excellent temporal (subsecond) and spatial resolution in behaving animals. FSCV has been described in detail elsewhere (Heien et al., 2005). Briefly, with FSCV the electrode potential is ramped to a value sufficient to oxidize dopamine and then returned to its initial value. Current is measured during the voltage ramp so that a current-voltage curve, termed a cyclic voltammogram, is generated. In more recent studies we now apply principal component regression to extract the dopamine concentration from the voltammetric data (Heien et al., 2005).

Using FSCV, we showed that dopamine is released in the core subregion of the NAc just prior to responding for natural and drug reward (Phillips et al., 2003; Roitman et al., 2004; Stuber et al., 2005). An example of this finding is illustrated in Figure 5. In this case, a significant increase in phasic dopamine was observed within seconds before, and immediately following, the reinforced response for intravenous cocaine during self-administration sessions. The increase in dopamine prior to the response is in line with the view that dopamine is necessary for the promotion of motivated behavior (Nicola et al., 2005; Phillips et al., 2003; Salamone et al., 2007). Interestingly, more recent work has shown that dopamine is actually diminished during intraoral infusion of an aversive tastant (quinine) (Carelli, 2005) and devalued natural rewards (Grigson, 2007). Perhaps this reduced signal then, acts to decrease the likelihood of future approach behaviors toward an aversive agent. However, it appears that a drug-predictive taste cue both reduces NAc dopamine and increases subsequent drug seeking (Grigson, 2007; Wheeler et al., 2008). This may appear at odds with the hypothesized role of dopamine in promoting reward-seeking behavior. The likely reason for this discrepancy is that the drugpredictive tastant is, itself, a primary reinforcer. We believe the altered dopamine release likely reflects the devaluation of the tastant and the presence of a negative affective state in anticipation of drug availability. As such, subsequent drug seeking may result as a way of correcting this negative hedonic state (Wheeler et al., 2008). Future studies will directly test this hypothesis. 


\subsection{Cocaine Abstinence Alters NAc Cell Firing}

Not only does cocaine experience modulate the activity of NAc neurons, but also removal of cocaine availability following repeated cocaine self-administration (abstinence) has profound effects on NAc cell firing. For example, West and colleagues reported that the activation of neurons in the NAc shell by a discriminative stimulus that was previously paired with cocaine availability is maintained after 3-4 weeks of abstinence (Ghitza et al., 2003). Likewise, in a series of studies in our laboratory we showed that removal of cocaine availability for one month has a marked effect on NAc activity. In our initial study (Hollander and Carelli, 2005), rats were trained to self-administer cocaine in $2 \mathrm{hr}$ daily sessions then divided into two groups. For one group (controls) NAc activity was recorded during two additional self-administration sessions completed over the next two days (test sessions $1 \& 2$ ). For the second group (1-month abstinence), NAc activity was recorded during one cocaine self-administration session completed the next day (test 1), and during a second self-administration session completed one month later (test 2). During the 1-month abstinence period animals remained in their homecages (no drug). As in prior reports, a subset of NAc neurons exhibited one of four types of patterned discharges within seconds of the cocaine reinforced response prior to abstinence. We have shown that these firing patterns reflect the encoding of information related to instrumental and Pavlovian contingencies operating within the task (for review see Carelli, 2004). Remarkably, our findings revealed that the percentage of neurons displaying patterned discharges dramatically increased (nearly 2-fold) in the core following 1-month abstinence. These findings revealed an enhanced activation of NAc neurons that encode cocaine-directed behaviors following prolonged drug abstinence.

In a subsequent study, we also showed that NAc core neurons are more responsive to cocaineassociated cues following 1-month abstinence (Hollander and Carelli, 2007). In this study, animals were trained to self-administer cocaine then returned to their home cages without cocaine access for either 1 day or 1 month. On the test day, all animals were placed back in the recording chamber, and during the first phase of the study 10 experimenter-controlled presentations of the tone-houselight stimulus previously associated with cocaine delivery were presented (no cocaine was given and the lever remained retracted during this phase). We showed that following 1-month abstinence, animals approached and spent more time in the quadrant of the chamber that previously contained the cocaine-associated lever following tonehouselight presentations (Figure 6A). In addition, a population of NAc neurons were either excited or inhibited by presentations of the tone-houselight stimulus (Figure 6B). Importantly, this activation was significantly greater following 1-month compared to 1-day abstinence from cocaine availability (Figure 6C). We further showed that the increased responsiveness of NAc neurons to cocaine-associated cues following abstinence was maintained in extinction trials during which rats responded for the cue in the absence of cocaine. Thus, 1-month abstinence from cocaine increases cocaine-seeking and enhances the activation of NAc neurons in the core during presentation of cocaine conditioned stimuli regardless of drug availability or contingency of cue delivery. As these effects were observed only in the core and not the shell of the NAc they complement previous findings of subregion specificity in NAc function for stimuli that predict cocaine versus the pharmacological effects of the drug (Di Ciano and Everitt, 2001; Fuchs et al., 2004; Parkinson et al., 1999).

Abstinence from cocaine self-administration has also been associated with 'incubation of craving' in which animals exhibit enhanced responding during extinction following experimenter-imposed abstinence (Bossert et al., 2005; Grimm et al., 2001). Clearly, our electrophysiological recordings support this view. Similar increases in sucrose-seeking behavior have been observed following sucrose abstinence (Grimm et al., 2002). Conversely, we failed to observe similar increased responding or an enhancement in NAc cell firing properties following abstinence from sucrose reinforcement (Jones et al., 2008). However, it 
is important to note that alterations in the dynamics of NAc cell firing following abstinence from natural rewards may be highly sensitive to experimental protocols and require 'binge' access sessions for the emergence of robust behavioral and neurophysiological changes (Avena et al., 2008). Nevertheless, our findings indicate that the dynamic increases in NAc cell firing following periods of abstinence are clearly observed for cocaine but not as robustly expressed for natural rewards.

\section{Role of Dopamine in Associative Learning}

Considerable evidence has accumulated that links dopamine activity in the NAc to reward learning. Several hypotheses of dopamine function have been proposed. For example, some hypothesize that NAc dopamine is essential for reward-related learning (Schultz, 1998; SmithRoe and Kelley, 2000), proper responses to incentive cues (Berridge and Robinson, 1998) or 'stamping in' reinforcing stimuli (Wise, 2004). These theories of dopamine's role in motivated behavior are all alike in they that suggest that dopamine facilitates associative learning, thus guiding future behavior. In support, dopamine function is critical for the acquisition of food seeking behavior (Smith-Roe and Kelley, 2000), but not the act of consummatory behavior (Grill and Norgren, 1978) or the hedonic expression of an animal engaged in consummatory behavior (Pecina et al., 1997).

One important view of dopamine function has been proposed by Wolfram Schultz and colleagues. Putative dopamine neurons exhibit increases in firing rates to the presentation of rewarding stimuli (Mirenowicz and Schultz, 1994). However, this response shifts to predictive stimuli for fully predicted rewards (Mirenowicz and Schultz, 1994). Conditioned responses of dopamine neurons are reward-specific and vary based on predicted magnitude and certainty (Cromwell and Schultz, 2003; Fiorillo et al., 2003; Mirenowicz and Schultz, 1996). Such findings support a role of dopamine as a reward prediction error signal. This hypothesis predicts that dopamine signaling is specific to unexpected rewards which constitute an error in reward expectancy and predicts that the signal shifts to cues that predict rewards. In support, we have recently shown that rapid dopamine release in the NAc tracks reward-related associations and subsequent motivated behavior for natural rewards (Day et al., 2007). An example of this finding is illustrated in Figure 7. Here, animals were trained on an autoshaping task wherein a lever (the CS+) was extended into the chamber for $10 \mathrm{~s}$ followed by sucrose delivery into a food receptacle. Interspersed between $\mathrm{CS}+$ trials was the presentation of a second lever (the $\mathrm{CS}^{-}$) that was also extended into the camber for 10 s but was not followed by reward delivery. As shown in Figure 7, rapid dopamine release was observed time locked predominately to the reward-associated CS+ cue; smaller dopamine release was observed to the CS- lever (likely related to generalization). Cue-elicited dopamine release events were observed in well-trained animals while phasic dopamine signals time-locked exclusively to reward delivery were measured during initial training trials. These findings support the view that NAc dopamine signaling is essential for reward learning that may function to ultimately guide motivated behavior for natural and drug rewards.

\section{Role of Dopamine in Modulating NAc Cell Firing during Behavior}

An important question investigated by our research group is how rapid dopamine release events may come to modulate the activation of NAc neurons during goal-directed behaviors. It has been proposed that the NAc is comprised of 'neuronal ensembles' or groups of cells with similar functional properties that are activated by synchronous excitation of their inputs (Pennartz et al., 1994). Clearly, our findings showing distinct subsets of NAc neurons that differentially process information about natural and drug reward, aversive stimuli, cues paired with cocaine reward, and reward predictors support this claim. 
How can dopamine activate discrete 'neuronal ensembles' in behaving animals? It has been proposed that dopamine acts as a neuromodulator in the NAc, gating the activation of NAc neurons by glutamatergic inputs from areas such as the basolateral amygdala, subiculum of the hippocampus and prefrontal cortex, and thereby influencing the output of the NAc (Carelli and Wightman, 2004; Mogenson et al., 1980; Nicola et al., 2000; Pennartz et al., 1994). Dopamine may influence the excitability of striatal and NAc neurons through multiple mechanisms. For example, medium-spiny neurons (which comprise approximately $90 \%$ of all NAc cells;

(Groves and Linder, 1983) exhibit a bistable membrane potential. These cells are typically not capable of exhibiting action potentials, but periodically exhibit 'up states' during which action potentials occur (O'Donnell, 2003). Dopamine facilitates such 'up states' while simultaneously reducing firing rate (Goto and O'Donnell, 2001). Such action increases the signal-to-baseline of phasically active NAc neurons thereby resulting in stronger efferent signals. Thus, dopamine functions to increase the sensitivity of neurons to either excitatory or inhibitory input, depending on striatal connectivity (Arbuthnott and Wickens, 2007). In fact, it has been recently been shown that spike-timing-dependent plasticity, wherein single EPSPs and single action potentials are paired to elicit synaptic plasticity, is dependent upon dopamine (Pawlak and Kerr, 2008).

In light of this, it is not surprising that our research group has revealed that rapid dopamine release events and phasic changes in NAc cell firing in behaving animals are coincident. Specifically, we use a combined electrophysiology/electrochemistry methodology that allows simultaneous measurements of rapid dopamine release using fast scan cyclic voltammetry and extracellular recordings of NAc neurons from the same carbon-fiber electrode during behavior (Cheer et al., 2007; Cheer et al., 2005). Using this approach, dopamine release and neuronal cell firing can be measured with the same temporal and spatial resolution and examined relative to discrete behavioral events. We have applied this technology to measure NAc activity and rapid dopamine release during intracranial self-stimulation (ICSS). For example, in one task, rats were trained to press a lever for intracranial stimulation following the onset of a distinct audiovisual cue that signaled lever extension. We show that for the majority of recordings, phasic cell firing occurred at the same locations in which rapid dopamine release was measured. An example of this finding is illustrated in Figure 8. In this case, the NAc neuron displayed a marked inhibition in cell firing during the cue that signaled impending lever extension; this inhibition continued during lever extension, depression and reward delivery. Interestingly, rapid dopamine release occurred within the same time period as changes in cell firing. We further showed that iontophoretic application of the dopamine D1 receptor antagonist, SCH23390 attenuated phasic cell firing during the task. Moreover, recording sites at which nonphasic cell firing was observed (i.e., cells exhibited no change in firing rate relative to the response) were generally the same locations at which no changes in rapid dopamine release were measured. Collectively, these studies lend strong support for a critical role of dopamine on a cellular level to modulate the activity of specific ensembles of NAc neurons that may ultimately function to guide goal-directed behavior. Additional studies are currently underway to examine if similar relationships between NAc cell firing and rapid dopamine release exist during goal-directed behaviors for cocaine or natural rewards.

\section{Neuroadaptation and Neural Signaling}

Experimental manipulations similar to those presented here have been shown to cause neuroadaptations in the NAc that may underlie the changes in signaling we report. For example, cocaine experience causes sensitization to cocaine and cocaine-associated cues (Ferrario et al., 2005; White and Kalivas, 1998; Wyvell and Berridge, 2001). This process is associated with increased dendritic spine density and surface AMPA expression in NAc neurons (Boudreau et al., 2007; Boudreau and Wolf, 2005; Robinson and Kolb, 1997, 2004) which suggests potentiated glutamatergic signaling following abstinence. Consistent with this, increased 
glutamate function is associated with increased drug taking (Boudreau and Wolf, 2005; Ferrario et al., 2005; McFarland et al., 2003). Analysis of the specificity within NAc signaling pathways across subregions may aid our understanding of the functional repercussions of such neuroadaptations. For example, the neuroadaptions underlying sensitization processes that have been linked to increased drug seeking have been specific to the core (Ferrario et al., 2005). Such regionally specific responses align with augmented drug-cue responses seen in electrophysiology studies. As noted above, phasic activation of NAc neurons in response to cocaine associated cues is potentiated selectively within the NAc core following abstinence (Hollander and Carelli, 2005, 2007). Thus the augmented signal could be a result of altered glutamatergic signaling from the prefrontal cortex or the basolateral amygdala to the NAc that drives drug seeking (Carelli et al., 2003; Kalivas and Hu, 2006; See, 2005).

While some have attributed increased cocaine seeking to sensitization processes, tolerance also coincides with augmented drug seeking. Chronic cocaine experience induces an elevated threshold for the self-administration of electrical brain stimulation of midbrain dopaminergic pathways, indicating a dampening of reward sensitivity (Ahmed et al., 2002; Kenny et al., 2003). It is thought that an upregulation of "anti-reward" brain systems in the NAc involving corticotrophin releasing factor and the kappa opioid system increase tolerance to the hedonic effects of cocaine and other drugs of abuse and promote escalated use (Ahmed and Koob, 1998; Koob and Le Moal, 2008; Walker and Koob, 2008; Walker et al., 2000). In support, it has been demonstrated that kappa opioid agonists reduce dopamine signaling the NAc (Britt and McGehee, 2008; Donzanti et al., 1992). It is possible that such alterations may explain the reduction in dopamine release for taste cues that predict cocaine availability. The continued investigation of drug-dependent neuroadaptive processes with the simultaneous analysis of differential signaling in the core and shell of the NAc will tease such motivational signals apart.

\section{Concluding Remarks}

Electrophysiological recordings in awake, behaving rats have provided important insight into the underlying cellular mechanisms in the NAc mediating reward, aversion, hedonics and goaldirected behaviors. Importantly, we have shown that the encoding of reward-related information is highly dynamic and influenced by a variety of factors including hedonic valence, reward comparison, cocaine abstinence and associative learning (Hollander and Carelli, 2007; Wheeler et al., 2008; Day et al., 2006; Carelli, 2000). Furthermore, electrochemical measurements of rapid dopamine signaling in the NAc have provided critical information on the role of dopamine in these processes. Using this approach, we have shown that in the awake animal dopamine signaling is not uniform within the NAc but that discrete subregions exist at which rapid dopamine release events occur (Wightman et al., 2007). Moreover, the release of dopamine within these discrete locations in behaving animals is also highly dynamic and influenced by factors such as associative learning. For example, rapid dopamine signaling occurs in the NAc to environmental cues predicative of natural (e.g., sucrose) reward following an operant response (Roitman et al., 2004), relative to lever press responding for cocaine as well as presentation of cocaine-associated cues (Phillips et al., 2003; Stuber et al., 2005) and during a Pavlovian conditioning task (Day et al., 2007). Furthermore, using a combined electrophysiology/electrochemistry technique we have revealed that places at which NAc neurons encode reward-related information are predominately the same locations at which rapid dopamine release is observed (Cheer et al., 2007; Cheer et al., 2005). As such, dopamine may function to modulate the activation of discrete functional microcircuits in the NAc that influence the encoding of reward-related information and ultimately drive goal-directed behaviors. Future studies will use these approaches to further dissect the neural circuitry underlying motivated behavior and thus provide a better understanding of the manner by which this system becomes dysfunctional in the cocaine addicted state. 


\section{Acknowledgments}

This research was supported by NIDA DA21055 to RAW, DA14339 and DA017318 to RMC. The authors thank Joshua Jones and Jeremy Day for helpful comments on the manuscript.

\section{References}

Ahmed SH, Kenny PJ, Koob GF, Markou A. Neurobiological evidence for hedonic allostasis associated with escalating cocaine use. Nat Neurosci 2002;5:625-626. [PubMed: 12055635]

Ahmed SH, Koob GF. Transition from moderate to excessive drug intake: change in hedonic set point. Science 1998;282:298-300. [PubMed: 9765157]

Arbuthnott GW, Wickens J. Space, time and dopamine. Trends Neurosci 2007;30:62-69. [PubMed: 17173981]

Avena NM, Bocarsly ME, Rada P, Kim A, Hoebel BG. After daily bingeing on a sucrose solution, food deprivation induces anxiety and accumbens dopamine/acetylcholine imbalance. Physiol Behav. 2008

Baldo BA, Kelley AE. Discrete neurochemical coding of distinguishable motivational processes: insights from nucleus accumbens control of feeding. Psychopharmacology (Berl) 2007;191:439-459. [PubMed: 17318502]

Baldo BA, Sadeghian K, Basso AM, Kelley AE. Effects of selective dopamine D1 or D2 receptor blockade within nucleus accumbens subregions on ingestive behavior and associated motor activity. Behav Brain Res 2002;137:165-177. [PubMed: 12445722]

Bassareo V, De Luca MA, Di Chiara G. Differential impact of pavlovian drug conditioned stimuli on in vivo dopamine transmission in the rat accumbens shell and core and in the prefrontal cortex. Psychopharmacology (Berl) 2007;191:689-703. [PubMed: 17072592]

Berridge KC, Robinson TE. What is the role of dopamine in reward: hedonic impact, reward learning, or incentive salience? Brain Res Brain Res Rev 1998;28:309-369. [PubMed: 9858756]

Berridge KC, Venier IL, Robinson TE. Taste reactivity analysis of 6-hydroxydopamine-induced aphagia: implications for arousal and anhedonia hypotheses of dopamine function. Behav Neurosci 1989;103:36-45. [PubMed: 2493791]

Bossert JM, Ghitza UE, Lu L, Epstein DH, Shaham Y. Neurobiology of relapse to heroin and cocaine seeking: an update and clinical implications. Eur J Pharmacol 2005;526:36-50. [PubMed: 16289451]

Boudreau AC, Reimers JM, Milovanovic M, Wolf ME. Cell surface AMPA receptors in the rat nucleus accumbens increase during cocaine withdrawal but internalize after cocaine challenge in association with altered activation of mitogen-activated protein kinases. J Neurosci 2007;27:10621-10635. [PubMed: 17898233]

Boudreau AC, Wolf ME. Behavioral sensitization to cocaine is associated with increased AMPA receptor surface expression in the nucleus accumbens. J Neurosci 2005;25:9144-9151. [PubMed: 16207873]

Bowman EM, Aigner TG, Richmond BJ. Neural signals in the monkey ventral striatum related to motivation for juice and cocaine rewards. J Neurophysiol 1996;75:1061-1073. [PubMed: 8867118]

Britt JP, McGehee DS. Presynaptic opioid and nicotinic receptor modulation of dopamine overflow in the nucleus accumbens. J Neurosci 2008;28:1672-1681. [PubMed: 18272687]

Carelli RM. Activation of accumbens cell firing by stimuli associated with cocaine delivery during selfadministration. Synapse 2000;35:238-242. [PubMed: 10657032]

Carelli RM. Nucleus accumbens cell firing during goal-directed behaviors for cocaine vs. 'natural' reinforcement. Physiol Behav 2002;76:379-387. [PubMed: 12117574]

Carelli RM, Ijames SG. Selective activation of accumbens neurons by cocaine-associated stimuli during a water/cocaine multiple schedule. Brain Res 2001;907:156-161. [PubMed: 11430899]

Carelli RM, Ijames SG, Crumling AJ. Evidence that separate neural circuits in the nucleus accumbens encode cocaine versus "natural" (water and food) reward. J Neurosci 2000;20:4255-4266. [PubMed: 10818162]

Carelli RM, Wightman RM. Functional microcircuitry in the accumbens underlying drug addiction: insights from real-time signaling during behavior. Curr Opin Neurobiol 2004;14:763-768. [PubMed: 15582381] 
Carelli RM, Williams JG, Hollander JA. Basolateral amygdala neurons encode cocaine selfadministration and cocaine-associated cues. J Neurosci 2003;23:8204-8211. [PubMed: 12967981]

Carelli RM, Wondolowski J. Selective encoding of cocaine versus natural rewards by nucleus accumbens neurons is not related to chronic drug exposure. J Neurosci 2003;23:11214-11223. [PubMed: 14657180]

Carelli, RMS.; G, S.; Heien, MLA.; Wightman, RM.; Roitman, MF. Examination of subsecond dopamine release to rewarding and aversive taste stimuli in a pavlovian conditioning paradigm. Proceeding of the Society For Neuroscience; San Diego: 2005.

Carlezon WA Jr, Wise RA. Rewarding actions of phencyclidine and related drugs in nucleus accumbens shell and frontal cortex. J Neurosci 1996;16:3112-3122. [PubMed: 8622141]

Cheer JF, Aragona BJ, Heien ML, Seipel AT, Carelli RM, Wightman RM. Coordinated accumbal dopamine release and neural activity drive goal-directed behavior. Neuron 2007;54:237-244. [PubMed: 17442245]

Cheer JF, Heien ML, Garris PA, Carelli RM, Wightman RM. Simultaneous dopamine and single-unit recordings reveal accumbens GABAergic responses: implications for intracranial self-stimulation. Proc Natl Acad Sci U S A 2005;102:19150-19155. [PubMed: 16380429]

Cromwell HC, Schultz W. Effects of expectations for different reward magnitudes on neuronal activity in primate striatum. J Neurophysiol 2003;89:2823-2838. [PubMed: 12611937]

Day JJ, Roitman MF, Wightman RM, Carelli RM. Associative learning mediates dynamic shifts in dopamine signaling in the nucleus accumbens. Nat Neurosci 2007;10:1020-1028. [PubMed: 17603481]

Day JJ, Wheeler RA, Roitman MF, Carelli RM. Nucleus accumbens neurons encode Pavlovian approach behaviors: evidence from an autoshaping paradigm. Eur J Neurosci 2006;23:1341-1351. [PubMed: 16553795]

Di Chiara G, Bassareo V, Fenu S, De Luca MA, Spina L, Cadoni C, Acquas E, Carboni E, Valentini V, Lecca D. Dopamine and drug addiction: the nucleus accumbens shell connection. Neuropharmacology 2004;47(Suppl 1):227-241. [PubMed: 15464140]

Di Ciano P, Everitt BJ. Dissociable effects of antagonism of NMDA and AMPA/KA receptors in the nucleus accumbens core and shell on cocaine-seeking behavior. Neuropsychopharmacology 2001;25:341-360. [PubMed: 11522463]

Donzanti BA, Althaus JS, Payson MM, Von Voigtlander PF. Kappa agonist-induced reduction in dopamine release: site of action and tolerance. Res Commun Chem Pathol Pharmacol 1992;78:193210. [PubMed: 1282270]

Ettenberg A, Camp CH. Haloperidol induces a partial reinforcement extinction effect in rats: implications for a dopamine involvement in food reward. Pharmacol Biochem Behav 1986;25:813-821. [PubMed: 3786340]

Everitt BJ, Robbins TW. Neural systems of reinforcement for drug addiction: from actions to habits to compulsion. Nat Neurosci 2005;8:1481-1489. [PubMed: 16251991]

Ferrario CR, Gorny G, Crombag HS, Li Y, Kolb B, Robinson TE. Neural and behavioral plasticity associated with the transition from controlled to escalated cocaine use. Biol Psychiatry 2005;58:751759. [PubMed: 16098484]

Fiorillo CD, Tobler PN, Schultz W. Discrete coding of reward probability and uncertainty by dopamine neurons. Science 2003;299:1898-1902. [PubMed: 12649484]

Flaherty, CF. Incentive Relativity. New York: Cambridge University Press; 1999.

Fuchs RA, Evans KA, Parker MC, See RE. Differential involvement of the core and shell subregions of the nucleus accumbens in conditioned cue-induced reinstatement of cocaine seeking in rats. Psychopharmacology (Berl) 2004;176:459-465. [PubMed: 15138757]

Ghitza UE, Fabbricatore AT, Prokopenko V, Pawlak AP, West MO. Persistent cue-evoked activity of accumbens neurons after prolonged abstinence from self-administered cocaine. J Neurosci 2003;23:7239-7245. [PubMed: 12917356]

Goto Y, O'Donnell P. Network synchrony in the nucleus accumbens in vivo. J Neurosci 2001;21:44984504. [PubMed: 11404437]

Grigson PS, Hajnal A. Once is too much: Conditioned changes in accumbal dopamine following a single saccharin-morphine pairing. Behavioral Neuroscience 2007;121:1234-1242. [PubMed: 18085877] 
Grigson PS, Twining RC. Cocaine-induced suppression of saccharin intake: a model of drug- induced devaluation of natural rewards. Behav Neurosci 2002;116:321-333. [PubMed: 11996317]

Grill HJ, Norgren R. Chronically decerebrate rats demonstrate satiation but not bait shyness. Science 1978;201:267-269. [PubMed: 663655]

Grimm JW, Hope BT, Wise RA, Shaham Y. Neuroadaptation. Incubation of cocaine craving after withdrawal. Nature 2001;412:141-142. [PubMed: 11449260]

Grimm JW, Shaham Y, Hope BT. Effect of cocaine and sucrose withdrawal period on extinction behavior, cue-induced reinstatement, and protein levels of the dopamine transporter and tyrosine hydroxylase in limbic and cortical areas in rats. Behav Pharmacol 2002;13:379-388. [PubMed: 12394414]

Groves PM, Linder JC. Dendro-dendritic synapses in substantia nigra: descriptions based on analysis of serial sections. Exp Brain Res 1983;49:209-217. [PubMed: 6832258]

Heien ML, Khan AS, Ariansen JL, Cheer JF, Phillips PE, Wassum KM, Wightman RM. Real-time measurement of dopamine fluctuations after cocaine in the brain of behaving rats. Proc Natl Acad Sci U S A 2005;102:10023-10028. [PubMed: 16006505]

Hollander JA, Carelli RM. Abstinence from cocaine self-administration heightens neural encoding of goal-directed behaviors in the accumbens. Neuropsychopharmacology 2005;30:1464-1474. [PubMed: 15856078]

Hollander JA, Carelli RM. Cocaine-associated stimuli increase cocaine seeking and activate accumbens core neurons after abstinence. J Neurosci 2007;27:3535-3539. [PubMed: 17392469]

Hyman SE, Malenka RC, Nestler EJ. Neural mechanisms of addiction: the role of reward-related learning and memory. Annu Rev Neurosci 2006;29:565-598. [PubMed: 16776597]

Ito R, Dalley JW, Howes SR, Robbins TW, Everitt BJ. Dissociation in conditioned dopamine release in the nucleus accumbens core and shell in response to cocaine cues and during cocaine-seeking behavior in rats. J Neurosci 2000;20:7489-7495. [PubMed: 11007908]

Ito R, Robbins TW, Everitt BJ. Differential control over cocaine-seeking behavior by nucleus accumbens core and shell. Nat Neurosci 2004;7:389-397. [PubMed: 15034590]

Jones JL, Wheeler RA, Carelli RM. Behavioral responding and nucleus accumbens cell firing are unaltered following periods of abstinence from sucrose. Synapse 2008;62:219-228. [PubMed: 18088061]

Kalivas PW, Hu XT. Exciting inhibition in psychostimulant addiction. Trends Neurosci 2006;29:610616. [PubMed: 16956674]

Kelley AE. Ventral striatal control of appetitive motivation: role in ingestive behavior and reward-related learning. Neurosci Biobehav Rev 2004;27:765-776. [PubMed: 15019426]

Kelley AE, Bakshi VP, Haber SN, Steininger TL, Will MJ, Zhang M. Opioid modulation of taste hedonics within the ventral striatum. Physiol Behav 2002;76:365-377. [PubMed: 12117573]

Kelley AE, Swanson CJ. Feeding induced by blockade of AMPA and kainate receptors within the ventral striatum: a microinfusion mapping study. Behav Brain Res 1997;89:107-113. [PubMed: 9475619]

Kenny PJ, Polis I, Koob GF, Markou A. Low dose cocaine self-administration transiently increases but high dose cocaine persistently decreases brain reward function in rats. Eur J Neurosci 2003;17:191195. [PubMed: 12534985]

Koob GF, Le Moal M. Addiction and the brain antireward system. Annu Rev Psychol 2008;59:29-53. [PubMed: 18154498]

Mahler SV, Smith KS, Berridge KC. Endocannabinoid hedonic hotspot for sensory pleasure: anandamide in nucleus accumbens shell enhances 'liking' of a sweet reward. Neuropsychopharmacology 2007;32:2267-2278. [PubMed: 17406653]

McFarland K, Lapish CC, Kalivas PW. Prefrontal glutamate release into the core of the nucleus accumbens mediates cocaine-induced reinstatement of drug-seeking behavior. J Neurosci 2003;23:3531-3537. [PubMed: 12716962]

Mirenowicz J, Schultz W. Importance of unpredictability for reward responses in primate dopamine neurons. J Neurophysiol 1994;72:1024-1027. [PubMed: 7983508]

Mirenowicz J, Schultz W. Preferential activation of midbrain dopamine neurons by appetitive rather than aversive stimuli. Nature 1996;379:449-451. [PubMed: 8559249] 
Mogenson GJ, Jones DL, Yim CY. From motivation to action: functional interface between the limbic system and the motor system. Prog Neurobiol 1980;14:69-97. [PubMed: 6999537]

Nicola SM, Surmeier J, Malenka RC. Dopaminergic modulation of neuronal excitability in the striatum and nucleus accumbens. Annu Rev Neurosci 2000;23:185-215. [PubMed: 10845063]

Nicola SM, Taha SA, Kim SW, Fields HL. Nucleus accumbens dopamine release is necessary and sufficient to promote the behavioral response to reward-predictive cues. Neuroscience 2005;135:1025-1033. [PubMed: 16165291]

Nicola SM, Yun IA, Wakabayashi KT, Fields HL. Firing of nucleus accumbens neurons during the consummatory phase of a discriminative stimulus task depends on previous reward predictive cues. J Neurophysiol 2004;91:1866-1882. [PubMed: 14645378]

O'Donnell P. Dopamine gating of forebrain neural ensembles. Eur J Neurosci 2003;17:429-435. [PubMed: 12581161]

Parkinson JA, Dalley JW, Cardinal RN, Bamford A, Fehnert B, Lachenal G, Rudarakanchana N, Halkerston KM, Robbins TW, Everitt BJ. Nucleus accumbens dopamine depletion impairs both acquisition and performance of appetitive Pavlovian approach behaviour: implications for mesoaccumbens dopamine function. Behav Brain Res 2002;137:149-163. [PubMed: 12445721]

Parkinson JA, Olmstead MC, Burns LH, Robbins TW, Everitt BJ. Dissociation in effects of lesions of the nucleus accumbens core and shell on appetitive pavlovian approach behavior and the potentiation of conditioned reinforcement and locomotor activity by D-amphetamine. J Neurosci 1999;19:24012411. [PubMed: 10066290]

Pawlak V, Kerr JN. Dopamine receptor activation is required for corticostriatal spike-timing-dependent plasticity. J Neurosci 2008;28:2435-2446. [PubMed: 18322089]

Pecina S, Berridge KC. Opioid site in nucleus accumbens shell mediates eating and hedonic 'liking' for food: map based on microinjection Fos plumes. Brain Res 2000;863:71-86. [PubMed: 10773195]

Pecina S, Berridge KC. Hedonic hot spot in nucleus accumbens shell: where do mu-opioids cause increased hedonic impact of sweetness? J Neurosci 2005;25:11777-11786. [PubMed: 16354936]

Pecina S, Berridge KC, Parker LA. Pimozide does not shift palatability: separation of anhedonia from sensorimotor suppression by taste reactivity. Pharmacol Biochem Behav 1997;58:801-811. [PubMed: 9329075]

Pecina S, Smith KS, Berridge KC. Hedonic hot spots in the brain. Neuroscientist 2006;12:500-511. [PubMed: 17079516]

Pennartz CM, Groenewegen HJ, Lopes da Silva FH. The nucleus accumbens as a complex of functionally distinct neuronal ensembles: an integration of behavioural, electrophysiological and anatomical data. Prog Neurobiol 1994;42:719-761. [PubMed: 7938546]

Phillips PE, Stuber GD, Heien ML, Wightman RM, Carelli RM. Subsecond dopamine release promotes cocaine seeking. Nature 2003;422:614-618. [PubMed: 12687000]

Reynolds SM, Berridge KC. Positive and negative motivation in nucleus accumbens shell: bivalent rostrocaudal gradients for GABA-elicited eating, taste "liking"/"disliking" reactions, place preference/avoidance, and fear. J Neurosci 2002;22:7308-7320. [PubMed: 12177226]

Reynolds SM, Berridge KC. Glutamate motivational ensembles in nucleus accumbens: rostrocaudal shell gradients of fear and feeding. Eur J Neurosci 2003;17:2187-2200. [PubMed: 12786986]

Robinson TE, Berridge KC. The neural basis of drug craving: an incentive-sensitization theory of addiction. Brain Res Brain Res Rev 1993;18:247-291. [PubMed: 8401595]

Robinson TE, Kolb B. Persistent structural modifications in nucleus accumbens and prefrontal cortex neurons produced by previous experience with amphetamine. J Neurosci 1997;17:8491-8497. [PubMed: 9334421]

Robinson TE, Kolb B. Structural plasticity associated with exposure to drugs of abuse. Neuropharmacology 2004;47(Suppl 1):33-46. [PubMed: 15464124]

Roitman MF, Stuber GD, Phillips PE, Wightman RM, Carelli RM. Dopamine operates as a subsecond modulator of food seeking. J Neurosci 2004;24:1265-1271. [PubMed: 14960596]

Roitman MF, Wheeler RA, Carelli RM. Nucleus accumbens neurons are innately tuned for rewarding and aversive taste stimuli, encode their predictors, and are linked to motor output. Neuron 2005;45:587-597. [PubMed: 15721244] 
Salamone JD, Correa M, Farrar A, Mingote SM. Effort-related functions of nucleus accumbens dopamine and associated forebrain circuits. Psychopharmacology (Berl) 2007;191:461-482. [PubMed: 17225164]

Schultz W. Predictive reward signal of dopamine neurons. J Neurophysiol 1998;80:1-27. [PubMed: 9658025]

See RE. Neural substrates of cocaine-cue associations that trigger relapse. Eur J Pharmacol 2005;526:140-146. [PubMed: 16253228]

Smith-Roe SL, Kelley AE. Coincident activation of NMDA and dopamine D1 receptors within the nucleus accumbens core is required for appetitive instrumental learning. J Neurosci 2000;20:77377742. [PubMed: 11027236]

Solomon RL, Corbit JD. An opponent-process theory of motivation. I. Temporal dynamics of affect. Psychol Rev 1974;81:119-145. [PubMed: 4817611]

Stuber GD, Wightman RM, Carelli RM. Extinction of cocaine self-administration reveals functionally and temporally distinct dopaminergic signals in the nucleus accumbens. Neuron 2005;46:661-669. [PubMed: 15944133]

Taha SA, Fields HL. Encoding of palatability and appetitive behaviors by distinct neuronal populations in the nucleus accumbens. J Neurosci 2005;25:1193-1202. [PubMed: 15689556]

Taha SA, Fields HL. Inhibitions of nucleus accumbens neurons encode a gating signal for reward-directed behavior. J Neurosci 2006;26:217-222. [PubMed: 16399690]

Walker BM, Koob GF. Pharmacological evidence for a motivational role of kappa-opioid systems in ethanol dependence. Neuropsychopharmacology 2008;33:643-652. [PubMed: 17473837]

Walker JR, Ahmed SH, Gracy KN, Koob GF. Microinjections of an opiate receptor antagonist into the bed nucleus of the stria terminalis suppress heroin self-administration in dependent rats. Brain Res 2000;854:85-92. [PubMed: 10784110]

Wheeler R, Roitman M, Grigson P, Carelli R. Single neurons in the nucleus accumbens track relative reward. International Journal of Comparative Psychology 2005;18:320-332.

Wheeler RA, Twining RC, Jones JL, Slater JM, Grigson PS, Carelli RM. Behavioral and electrophysiological indices of negative affect predict cocaine self-administration. Neuron 2008;57:774-785. [PubMed: 18341996]

White FJ, Kalivas PW. Neuroadaptations involved in amphetamine and cocaine addiction. Drug Alcohol Depend 1998;51:141-153. [PubMed: 9716936]

Wightman RM, Heien ML, Wassum KM, Sombers LA, Aragona BJ, Khan AS, Ariansen JL, Cheer JF, Phillips PE, Carelli RM. Dopamine release is heterogeneous within microenvironments of the rat nucleus accumbens. Eur J Neurosci 2007;26:2046-2054. [PubMed: 17868375]

Wise RA. Dopamine, learning and motivation. Nat Rev Neurosci 2004;5:483-494. [PubMed: 15152198]

Wise RA, Bozarth MA. A psychomotor stimulant theory of addiction. Psychol Rev 1987;94:469-492. [PubMed: 3317472]

Wise RA, Raptis L. Effects of naloxone and pimozide on initiation and maintenance measures of free feeding. Brain Res 1986;368:62-68. [PubMed: 3955365]

Wise RA, Rompre PP. Brain dopamine and reward. Annu Rev Psychol 1989;40:191-225. [PubMed: 2648975]

Wise RA, Spindler J, deWit H, Gerberg GJ. Neuroleptic-induced "anhedonia" in rats: pimozide blocks reward quality of food. Science 1978;201:262-264. [PubMed: 566469]

Wise RA, Yokel RA, DeWit H. Both positive reinforcement and conditioned aversion from amphetamine and from apomorphine in rats. Science 1976;191:1273-1275. [PubMed: 1257748]

Wyvell CL, Berridge KC. Incentive sensitization by previous amphetamine exposure: increased cuetriggered "wanting" for sucrose reward. J Neurosci 2001;21:7831-7840. [PubMed: 11567074]

Yun IA, Wakabayashi KT, Fields HL, Nicola SM. The ventral tegmental area is required for the behavioral and nucleus accumbens neuronal firing responses to incentive cues. J Neurosci 2004;24:2923-2933. [PubMed: 15044531] 
A
Sucrose

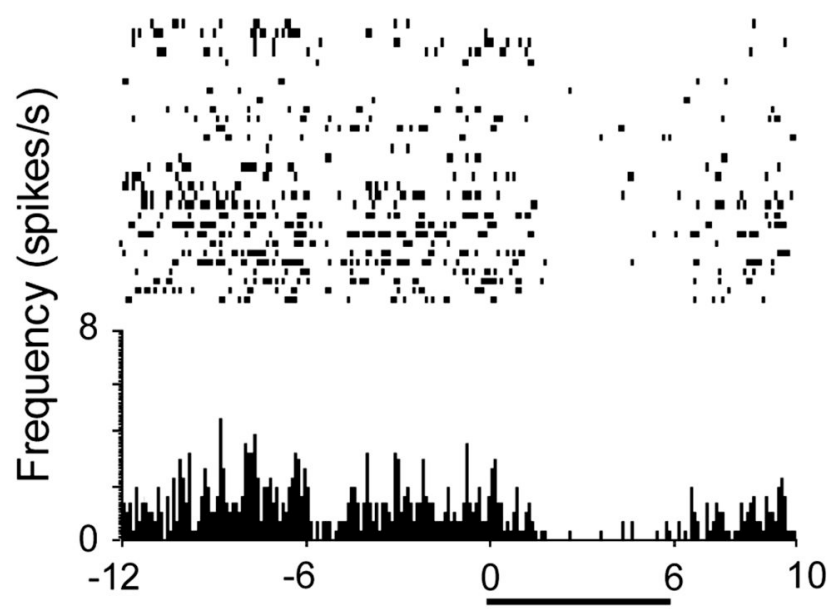

B

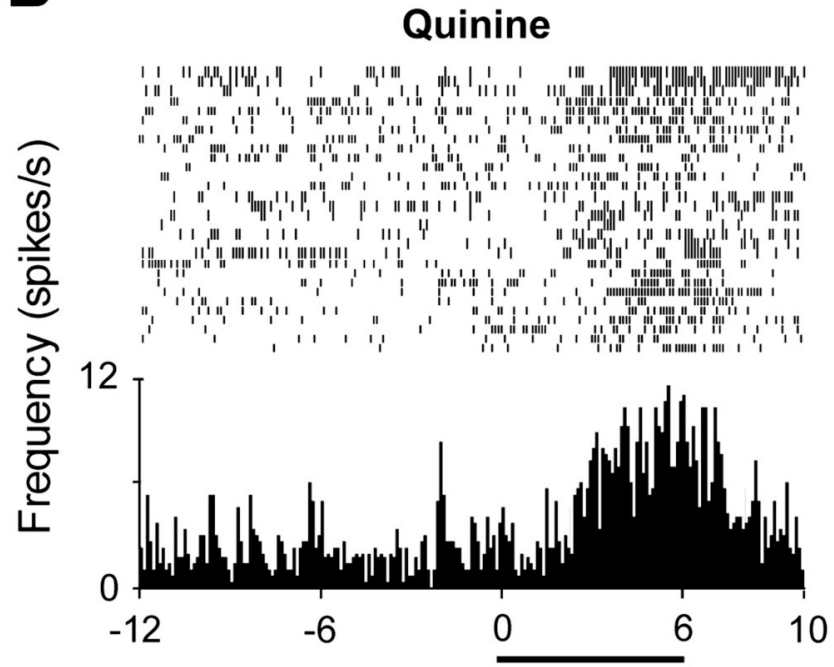

D

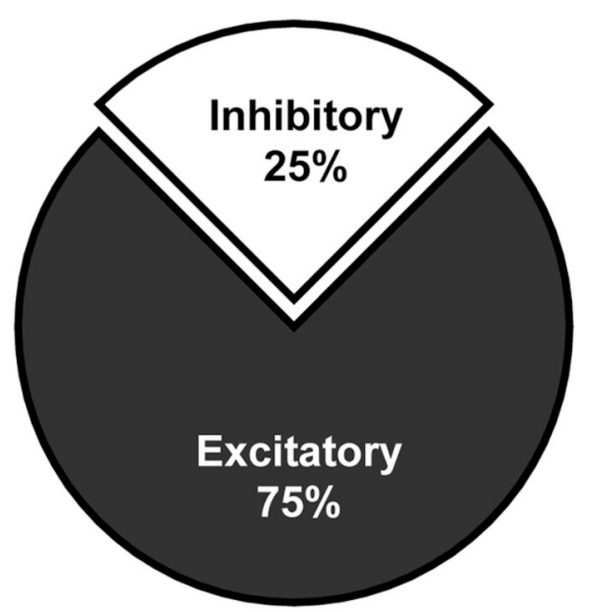

Figure 1.

NAc neurons exhibit opposite firing patterns during intraoral infusion of rewarding versus aversive tastants. Top: The activity of a representative NAc cell that exhibited a decrease in firing rate during infusion of a sweet sucrose solution (A), and another NAc neuron that showed a clear increase in activity during intraoral infusions of a bitter quinine solution (B). Pump onset at time 0 in $\mathrm{PEH}$; horizontal black bar indicates intraoral infusion duration. The piecharts show the percentage of all recorded NAc neurons that displayed either excitatory or inhibitory responses to intraoral infusions of sucrose (C) or quinine (D). Figure modified from Roitman et al. (2005) with permission from Elsevier. 
A

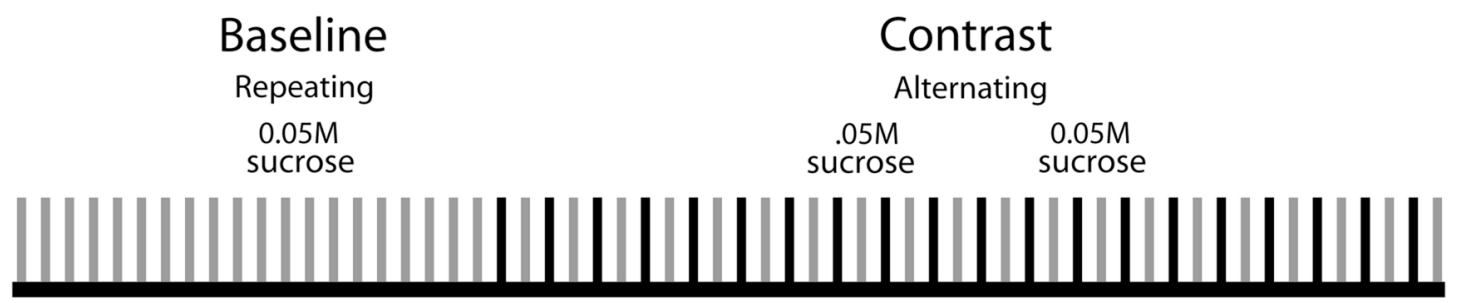

$60 \mathrm{~min}$

B
Baseline

$0.05 \mathrm{M}$ sucrose

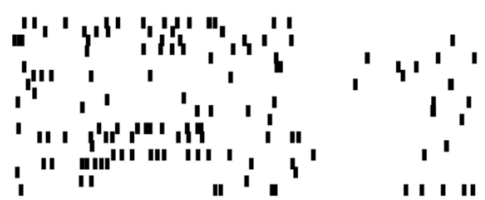

Contrast

$0.05 \mathrm{M}$ sucrose

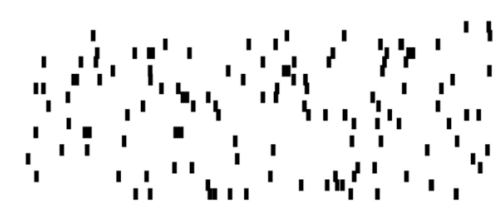

$3-$

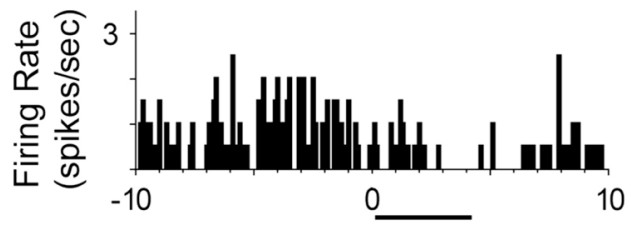

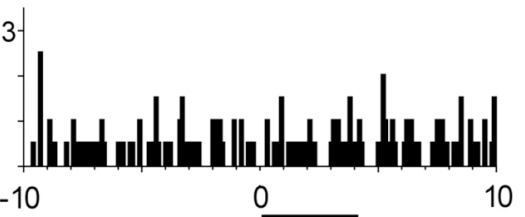

Contrast

$0.5 \mathrm{M}$ sucrose

Figure 2.

Dynamic modulation of NAc cell firing during reward comparison involving two natural rewards. A. Design of the behavioral task. A low concentration of sucrose $(0.05 \mathrm{M})$ was repeatedly delivered via intraoral infusion during the baseline period. Next, the same concentration of sucrose was delivered, but in alternation with a higher, more palatable solution $(0.5 \mathrm{M})$. Each tick mark represents an infusion of the low (grey) or high sucrose concentration (black). B. The baseline response of one cell to infusions of the $0.05 \mathrm{M}$ sucrose was a pronounced reduction in firing rate (left). However, the same cell exhibited no change in activity to the same sucrose solution (middle) when given in an alternating manner with the more palatable solution (right). Time 0 indicates infusion onset; horizontal black bar below each PEH indicates the duration of the intraoral infusion. 
A

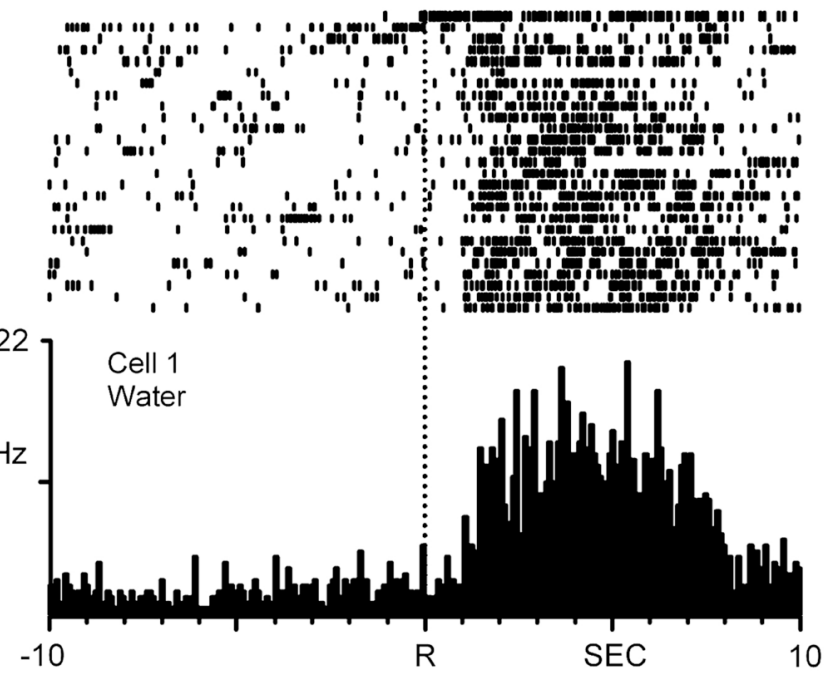

C
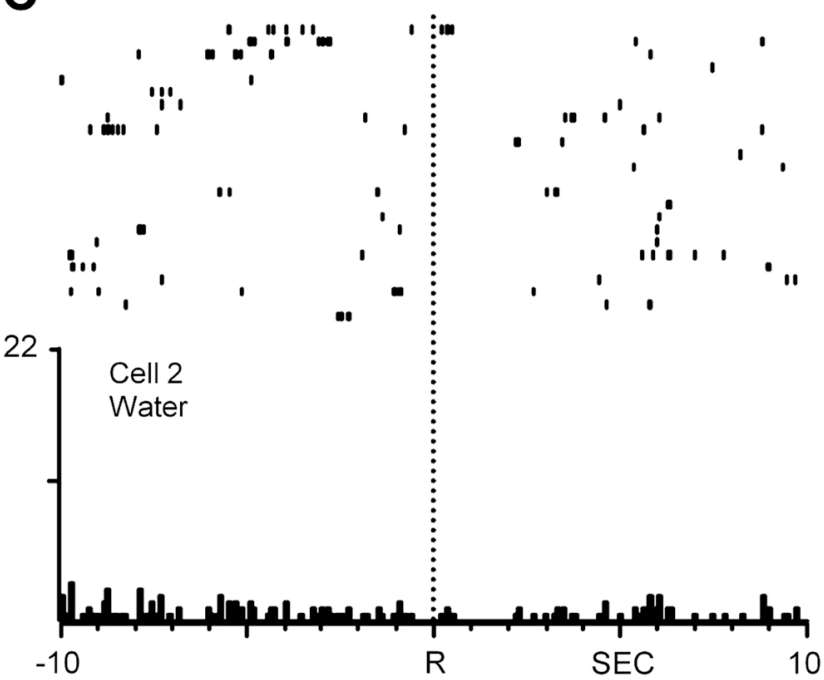

B

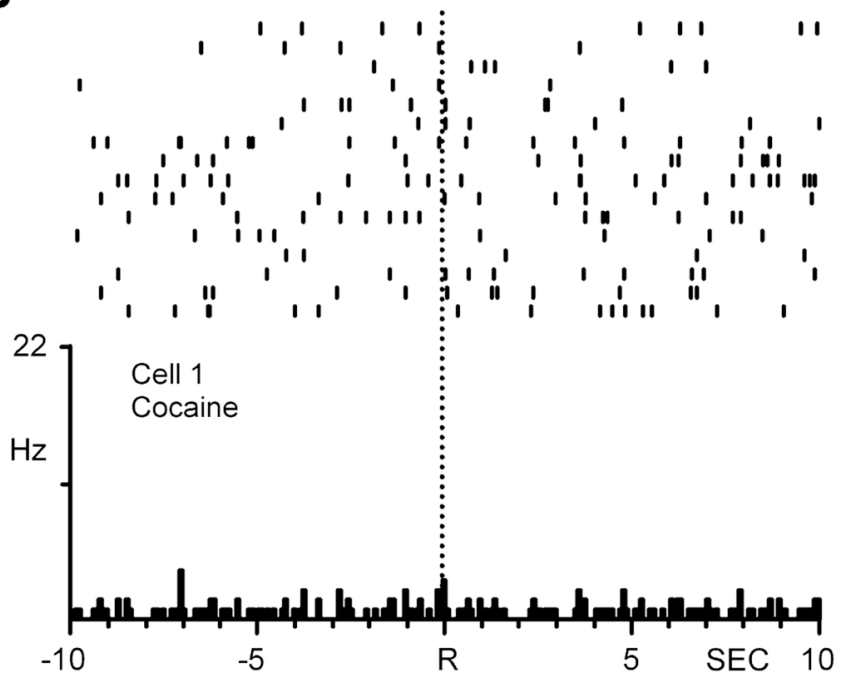

D
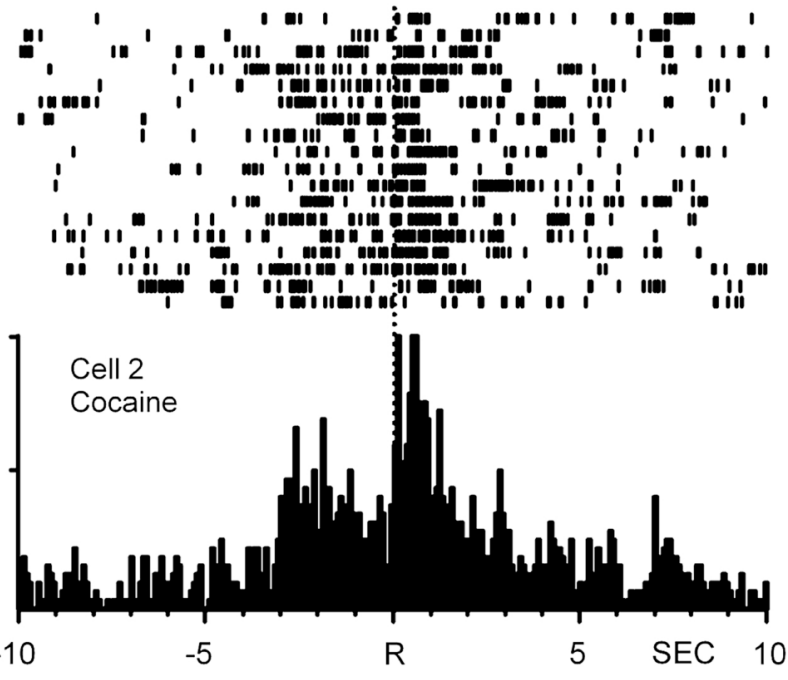

Figure 3.

NAc neurons exhibit differential, nonoverlapping firing patterns during goal-directed behaviors for natural (water) versus cocaine reward. Left: PEHs show the activity of a single neuron that exhibited increases in firing rate immediately following lever press responding for water reinforcement (A) but no changes in activity (i.e., nonphasic firing) relative to the reinforced response for intravenous cocaine during the self-administration phase of the multiple schedule. (B). Right: Another NAc neuron recorded in a second animal exhibited nonphasic firing during the water-reinforcement phase and a shift to patterned firing during selfadministration. Drug infusion indicated by horizontal lines below bottom PEHs. R is reinforced response. Figure modified from Carelli et al. (2003). Copyright 2003 by the Society for Neuroscience. 
A

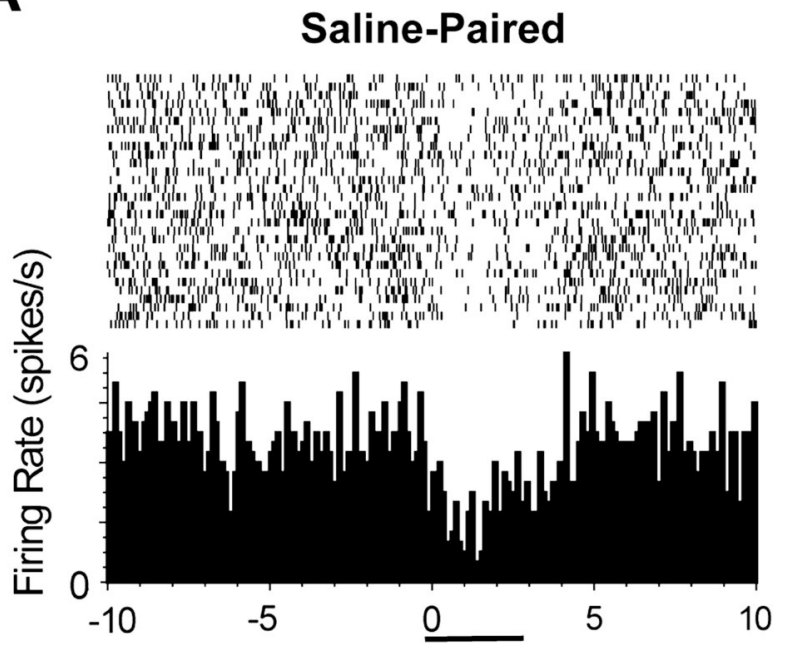

C

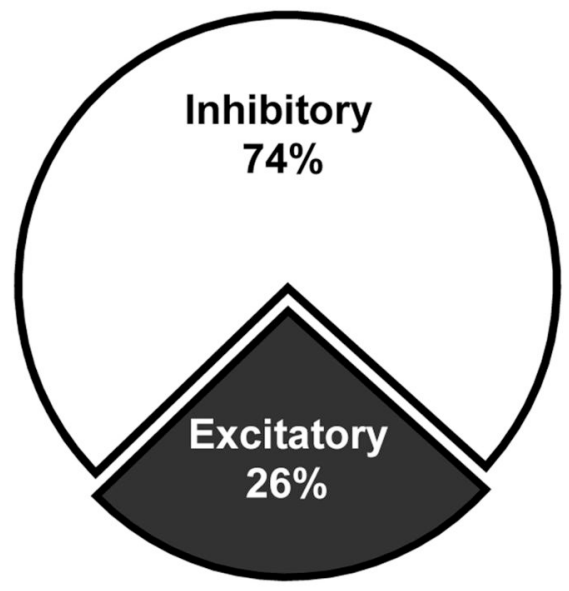

B

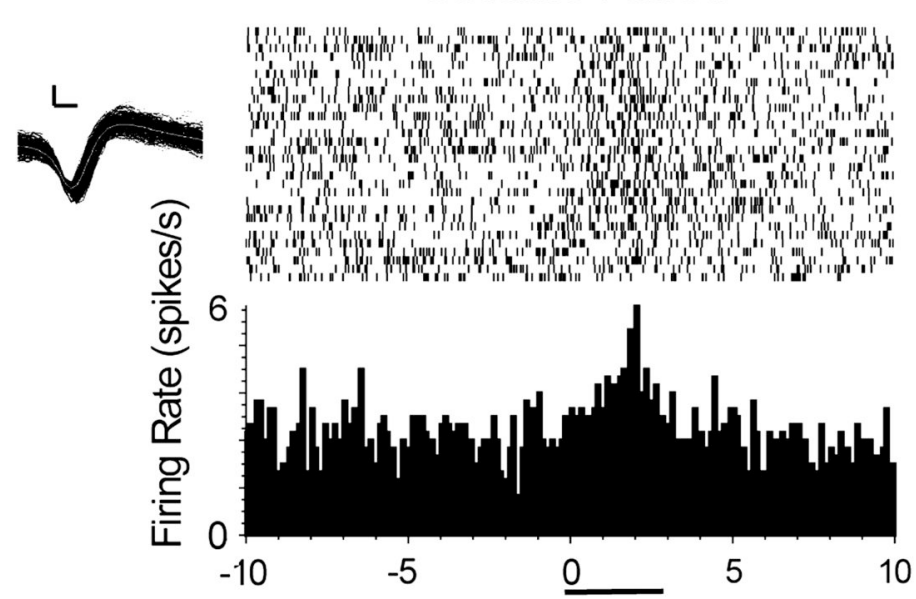

D

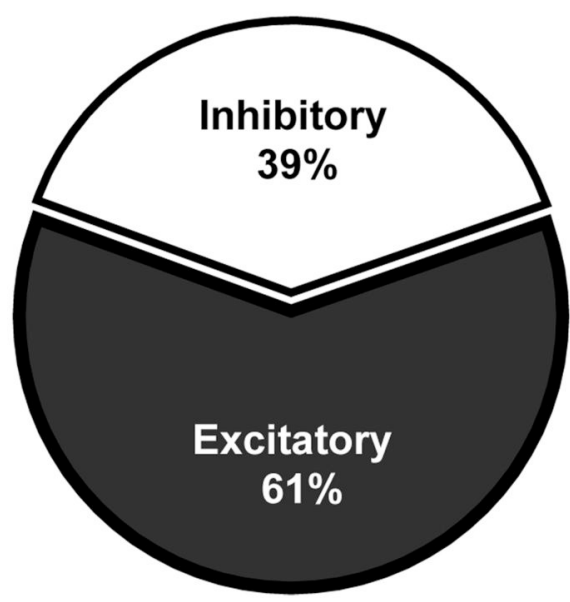

Figure 4.

NAc neurons track a learned aversion to saccharin following its repeated pairing with cocaine. Top: A: PEH of a representative NAc neuron that exhibited a decrease in firing rate during intraoral infusion of a distinctly flavored saccharin infusion that predicted availability to selfadminister saline. B: The same neuron shifted its firing profile to an excitatory response during infusion of a differently flavored saccharin solution of the same concentration that was repeatedly paired with cocaine self-administration. (Inset) Scale calibration: $26 \mathrm{mV}, 100 \mathrm{~ms}$. Bottom; The piecharts show that the majority of NAc neurons exhibited inhibitory responses to the tastant paired with saline self-administration $(\mathrm{C})$, but shifted to predominately excitatory activity during infusion of the tastant paired with cocaine self-administration (D). Figure modified from Wheeler et al. (2008) with permission from Elsevier. 


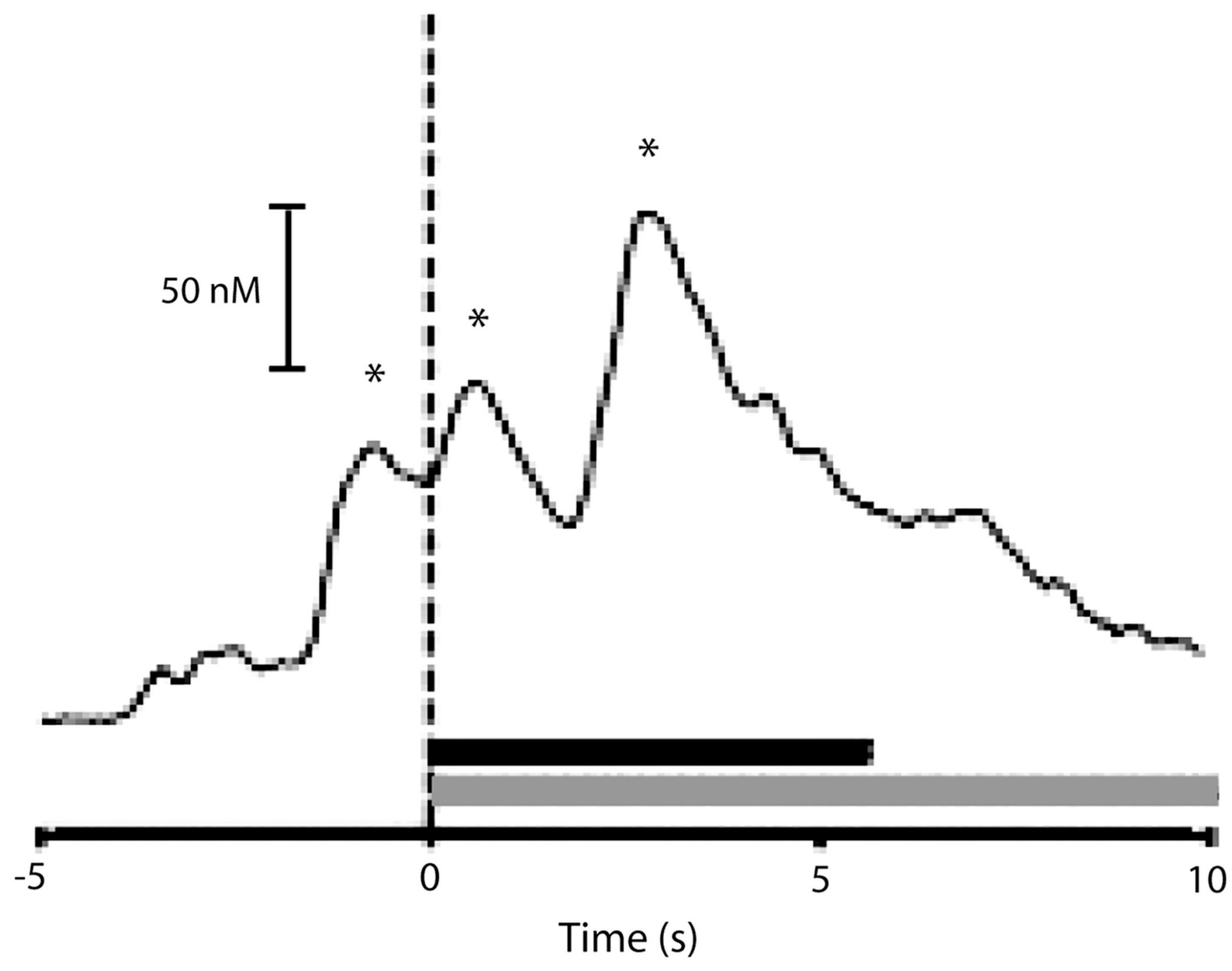

Figure 5.

Rapid dopamine release is evident within seconds of reinforced responding for cocaine during self-administration sessions. Dopamine significantly increased within seconds preceding and immediately following the cocaine reinforced lever press response (dashed line, time 0 ). One representative trial shown. Black bar indicates the duration of cocaine infusion $(0.33 \mathrm{mg} / \mathrm{inf})$; shaded bar indicates the presentation of the drug-associated cues. Asterisks indicate confirmed dopamine events. Figure modified from Stuber et al. (2005) with permission from Elsevier. 


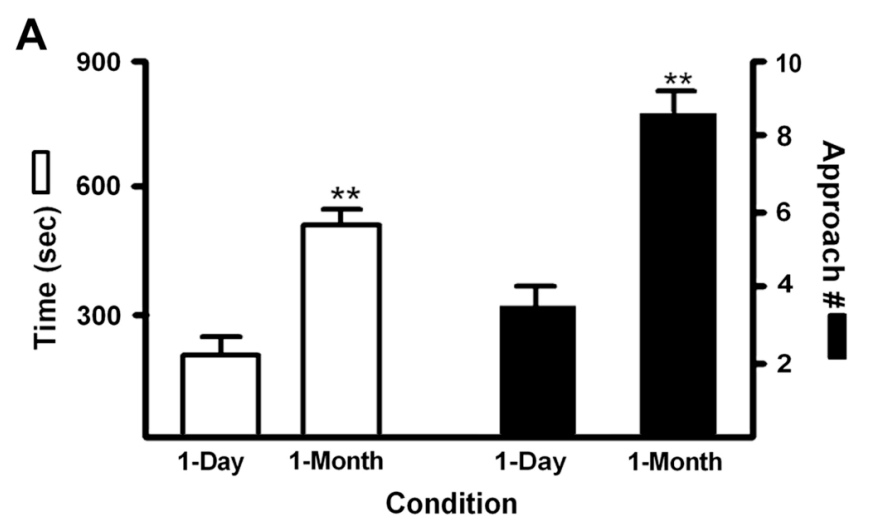

B
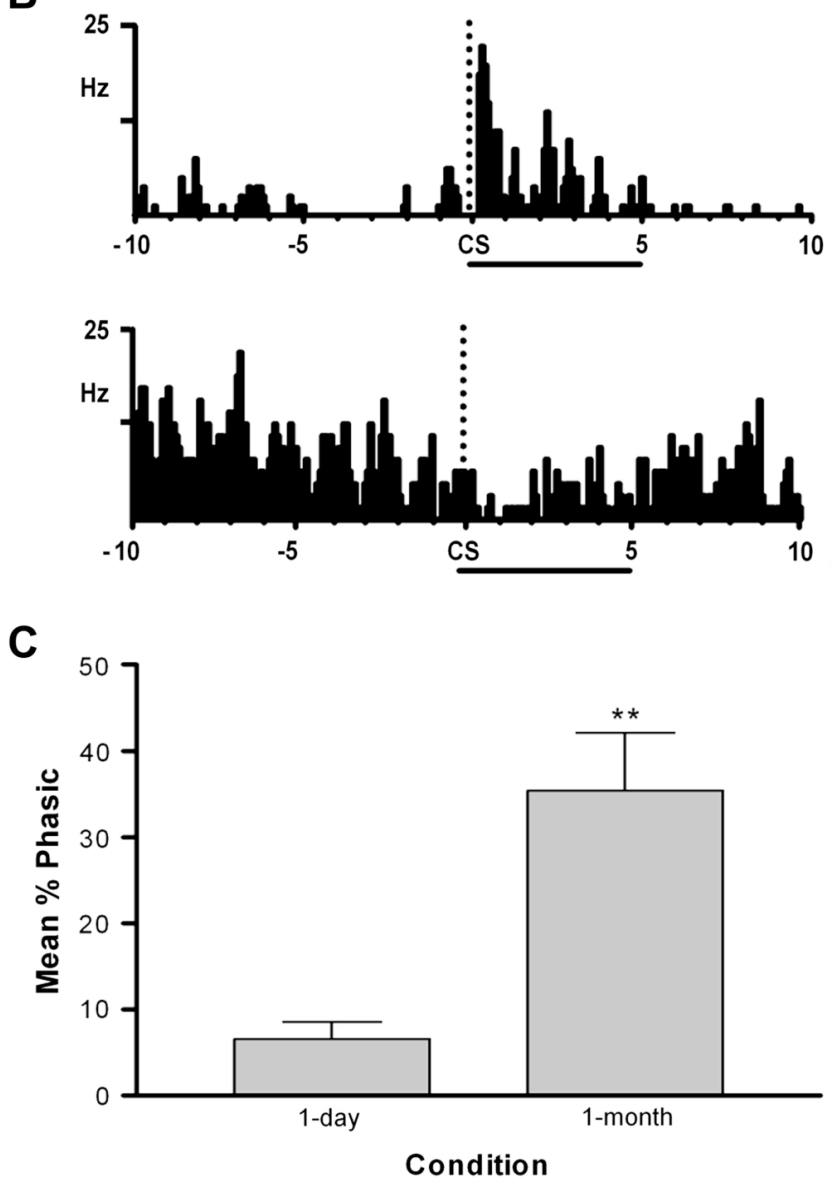

Figure 6.

One-month abstinence from cocaine self-administration increases the percentage of NAc neurons that respond to cocaine-associated cues (CS). A. CS-induced behavioral activation (time in, and number of approaches to, cocaine-associated lever quadrant). B. PEHs show examples of representative neurons exhibiting excitatory (top) or inhibitory (bottom) responses to the CS ( $5 \mathrm{~s}$ duration; onset indicated by dashed line labeled 'CS' in each PEH). C. Percentage of NAc neurons that were significantly activated by the CS for $1 \mathrm{~d}$ and 1 month cocaine abstinent rats. ${ }^{* *} p<0.01$. Figure from Hollander et al. (2007). Copyright 2007 by the Society for Neuroscience. 

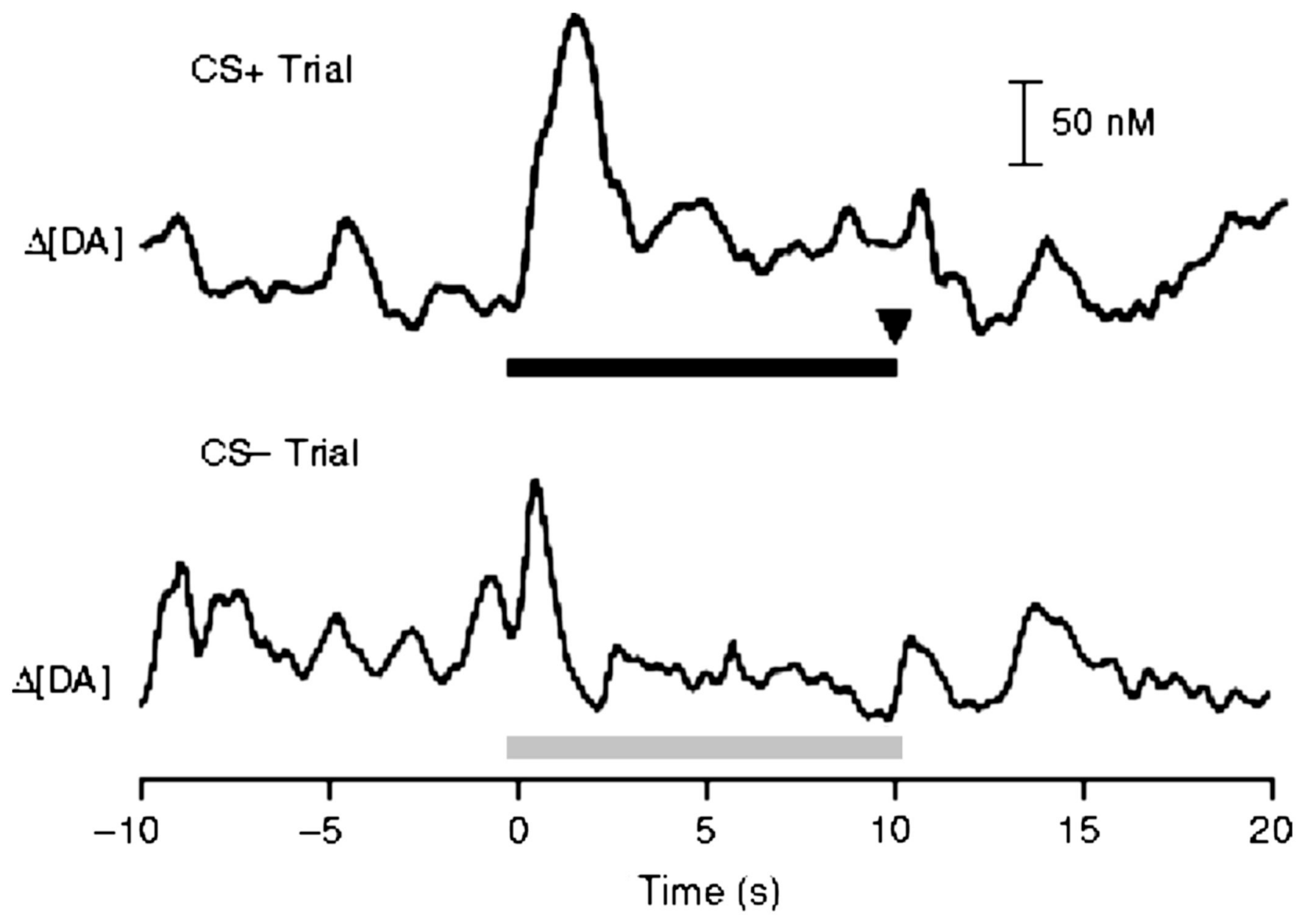

Figure 7.

After training, rapid dopamine release events in the NAc shift from the onset of primary (sucrose) reward to conditioned stimuli (CS) associated with reward delivery. Top:

Representative changes in dopamine signaling during a trial in which the CS+ (top) signaled reward delivery (at inverted arrow). The horizontal black bar indicates the duration of the CS +. Bottom: Smaller dopamine release event during a trial in which the $\mathrm{CS}-$ signaled no reward delivery. The horizontal grey bar indicates the duration of the $\mathrm{CS}^{-}$. Figure modified from Day et al. (2007) with permission from Nature Publishing Group. 


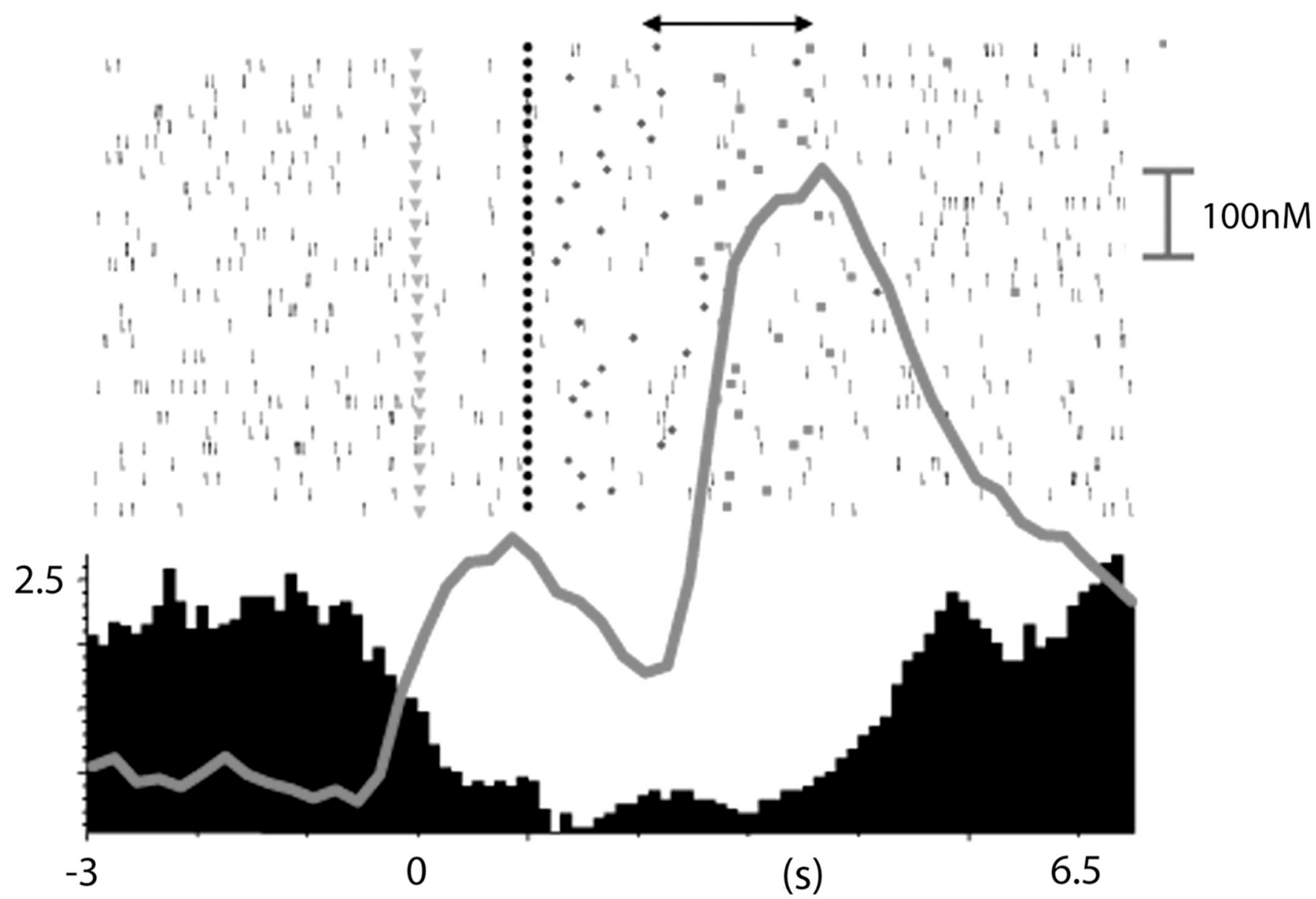

Figure 8.

Combined electrophysiological and electrochemical measurements reveal similar temporal dynamics of rapid dopamine release and NAc cell firing during intracranial self-stimulation. The overlaid trace (grey) shows the time course of extracellular dopamine concentration changes simultaneously measured at the same location where a NAc neuron was recorded. Note that changes in rapid dopamine release events occurred during the period at which the NAc neuron exhibited a phasic inhibition in cell firing. Cue onset at time 0 ; lever extension at 1s; gray symbols in raster represent lever presses; stimulation delivery indicated by symbols under double arrow in raster display. Figure modified from Cheer et al. (2008) with permission from Elsevier. 